\title{
Aprendizagem colaborativa através do uso do Glogster nas aulas de Biologia
}

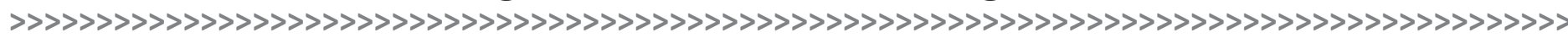

Pâmela Ziliotto Sant'Anna Flach*

\section{Resumo:}

A sociedade contemporânea vivencia uma constante e rápida mudança nas tecnologias da informação e comunicação, mudança que estabelece novas relações entre conhecimento, ensino e aprendizagem. Com isso, é fundamental que os estudantes sejam preparados para utilizar os recursos tecnológicos com autonomia, a fim de lidar com a intensa explosão de informações de maneira cooperativa. O presente trabalho relata a experiência de construção de glogs, pôsteres interativos, através do uso da ferramenta online Glogster, explorando o seu potencial para estimular a aprendizagem colaborativa em Biologia. O estudo foi realizado com alunos do terceiro ano do Ensino Médio em uma escola da Rede Pública de ensino em Porto Alegre, RS.

\section{Palavras-chave:}

Biologia. Aprendizagem colaborativa. Glogs. Glogster.

\begin{abstract}
:
The contemporary society has experienced a constant and fast change in information and communication technologies that sets new relationships among knowledge, learning and teaching. Thus, it is essential that students be prepared to use the technological resources independently and to deal with the intense explosion of information in a cooperative way. This paper reports the experience of building Glogs, interactive posters, through the use of the online tool Glogster, using its potential to stimulate collaborative learning in Biology. The study was conducted with students of the third grade of a public high school in Porto Alegre, RS.
\end{abstract}

\section{Keywords:}

Biology. Collaborative learning. Glogs. Glogster.

\section{Introdução}

As diferentes propostas acerca dos processos de ensino e aprendizagem reconhecem, hoje em dia, que os mais variados valores humanos não são alheios ao aprendizado científico e que a Ciência deve ser aprendida em suas relações com a Tecnologia e com as demais questões sociais e ambientais. Partindo desse pressuposto, é necessária a formação de sujeitos competentes, que saibam utilizar diferentes fontes de informação e recursos tecnológicos para adquirir e construir conhecimentos, questionar a realidade formulando problemas e buscando resolvê-los, utilizando para isso: o pensamento lógico, a criatividade, a capacidade de análise crítica; selecionando procedimentos e verificando sua adequação
* > Bacharel e Licenciada em Ciências Biológicas, Mestre em Ecologia. Professora de Biologia na Rede Estadual de ensino em Porto Alegre. E-mail: pamelazsf@ gmail.com. 
(BRASIL, 1998, p. 8). Assim, formar para a vida significa mais do que reproduzir dados, determinar classificações ou identificar símbolos: significa saber se informar, comunicar-se, argumentar, compreender e agir; enfrentar problemas de diferentes naturezas; participar socialmente de forma prática e solidária; ser capaz de elaborar críticas e/ou propostas; e, especialmente, adquirir uma atitude de permanente aprendizado (BRASIL, 2002, p. 6).

No entanto, verifica-se que nem sempre o ensino promovido no ambiente escolar permite que os estudantes se apropriem dos conhecimentos de modo a compreendê-los, questioná-los e utilizá-los como instrumentos do pensamento que extrapolem situações de ensino e aprendizagem eminentemente escolares (PEDRANCINI et al., 2007, p. 300). Muitas práticas, ainda hoje, são fundamentadas na transmissão e reprodução de informações, tendo como principal recurso o livro didático e a sua transcrição no quadro, enquanto poucas práticas incorporam os avanços científicos produzidos nas últimas décadas. Dessa forma, grande parte do saber transmitido na escola é rapidamente esquecido, prevalecendo ideias alternativas ou de senso comum bastante estáveis e resistentes, identificadas, inclusive, entre estudantes universitários (MORTIMER, 1996, p. 21).

No que se refere ao ensino de Biologia, não raro, verifica-se nas escolas que este se caracteriza pela transmissão de conteúdos através de aulas expositivo-dialogadas, suportadas por livros didáticos, com o predomínio de atividades de fixação e memorização de conceitos, em detrimento da compreensão dos fenômenos biológicos, para explicar o funcionamento do mundo e para intervir na realidade. Tais procedimentos acabam não contribuindo, significativamente, para a construção da autonomia devido ao fato de não colocarem o aluno no centro do processo.

Logo, se almejamos uma educação como forma de fomentar múltiplas leituras de mundo, e não mais como depósito de informações, precisamos ser inovadores e estimular o espírito crítico, a criatividade, a autonomia, a cidadania (FREIRE, 2011, p. 81). Nessa perspectiva, as tecnologias digitais permitem uma mudança no papel do professor, de único detentor do conhecimento, para mediador no processo de aprendizagem, conferindo ao aluno a condição de sujeito ativo na construção do conhecimento, em que a coautoria, a criatividade, a pró-atividade e a postura colaborativa são priorizados. Lévy (1993, p. 88-89) considera que tais tecnologias são tecnologias da inteligência, por se tratarem de novas ferramentas cognitivas que possibilitam um salto qualitativo em nossas possibilidades de raciocínio e apreensão do conhecimento. O autor destaca a importância da utilização de tecnologias como uma ferramenta de pensamento, no sentido de que, ao se articularem com o sistema cognitivo do sujeito, o ajudam a se constituir cognitiva e subjetivamente.

A inserção da tecnologia na sala de aula pode ajudar a formar um aluno mais autônomo e construtor do conhecimento, promovendo a colaboração e a troca recíproca entre os alunos. O termo colaborativo sugere a ideia de "trabalhar com", numa abordagem na qual as tarefas são realizadas por todos num contínuo de partilha, diálogo e negociação, sendo a aprendizagem colaborativa uma atividade na qual os alunos e o professor constroem cooperativamente um modelo explícito de conhecimento (CARVALHO, 2007, p. 31).

A construção colaborativa pode ser promovida por meio de diversos recursos digitais que permitem a criação de ambientes de aprendizagem pautados pela cooperação, com a possibilidade de construção de redes de conhecimento, as quais podem ser ampliadas a qualquer momento. Tais recursos promovem trocas e interações desencadeadoras de aprendizagem ao estimular a valorização da identidade, a tomada de decisões em conjunto, a troca de informações e a reelaboração do conhecimento.

Dentro dessa perspectiva, uma possibilidade de uso das tecnologias com fins educativos consiste em trabalhar com a construção de glogs, pôsteres interativos que podem ser acessados através do website Glogster ${ }^{2}$. O Glogster constitui-se de uma plataforma colabora-

2 > Disponível em: http://edu.glogster. com. Acesso em: abr./ maio 2012 tiva online para professores e alunos compartilharem suas experiências, ideias, seus textos, suas imagens, seus áudios, links, vídeos, funcionando como um ambiente de colaboração. 
A partir disso, o presente trabalho investiga a utilização da ferramenta Glogster para a construção de pôsteres online, os glogs, como estratégia de promoção de situações enriquecedoras de aprendizagem individual e colaborativa, através de recursos tecnológicos. Buscando avaliar as possibilidades pedagógicas do uso do Glogster, é relatada a experiência realizada na disciplina de Biologia, com alunos do terceiro ano do Ensino Médio, em uma escola da Rede Pública de ensino em Porto Alegre, RS. Os principais objetivos deste relato são avaliar a aplicação dos glogs no ensino de Biologia e discutir as suas potencialidades acerca da contribuição e do incentivo à aprendizagem colaborativa.

\section{Descrição do estudo}

A integração dos glogs na disciplina de Biologia teve como objetivo explorar as potencialidades dessa ferramenta enquanto recurso e estratégia pedagógica. Com isso, objetivou-se criar situações de aprendizagem colaborativa, promovendo o uso da tecnologia em sala de aula como recurso para sistematização, organização e divulgação das aprendizagens e dos conhecimentos construídos.

Os glogs foram produzidos em duplas ou trios. Durante esse processo, foram analisadas: a participação dos sujeitos, a organização do trabalho, a negociação e a liderança, bem como a organização dos registros das aprendizagens dos alunos. A atividade foi realizada no primeiro semestre de 2013, abordando conceitos de ecologia e biomas.

O trabalho foi desenvolvido em etapas, sendo a primeira realizada através de aulas expositivas dialogadas acerca dos conceitos ecológicos básicos e dos problemas ambientais decorrentes da atividade humana. Num segundo momento, foram apresentados os principais biomas mundiais e brasileiros, os quais deveriam ser pesquisados pelos alunos em duplas ou trios. A pesquisa deveria envolver tópicos essenciais, como as características bióticas e abióticas do bioma, a localização geográfica, as relações ecológicas estabelecidas entre as principais espécies que ocorrem no bioma e, também, a construção de teias alimentares com as espécies nativas do bioma estudado. Impactos ambientais associados ao bioma também foram pesquisados e discutidos em sala de aula. Num terceiro momento, os alunos registraram suas aprendizagens com a pesquisa através dos glogs. Ao término dessa atividade, os glogs foram compartilhados, exibidos, e as informações referentes aos biomas estudados foram discutidas e contextualizadas em aula.

Por fim, foram desenvolvidos e aplicados aos alunos dois questionários para coleta de dados. O primeiro questionário, de caracterização da amostra, objetivou identificar o perfil dos alunos, a disponibilidade de acesso ao computador e à internet e a frequência, além dos principais usos que os mesmos fazem destes recursos. O segundo questionário foi preenchido ao final da realização da atividade com o Glogster objetivando investigar as percepções dos alunos em relação ao uso, às aplicações e potencialidades dessa ferramenta.

\section{Caracterização da amostra}

O estudo envolveu 95 alunos, sendo 55 do sexo feminino e 40 do sexo masculino, de cinco turmas do terceiro ano do Ensino Médio, com idades entre 16 anos (59\%), 17 anos (32\%) e 18 anos (9\%), sendo que desse grupo apenas quatro alunos reprovaram em algum ano do Ensino Médio.

Com base no questionário, foi possível identificar que $100 \%$ dos alunos possui computador em casa com acesso à Internet. A grande maioria dos alunos (93\%) revelou gostar de usar o computador e ter facilidades para trabalhar com ele e para navegar na Internet. Em relação à frequência de utilização do computador para navegação na Internet como forma 
de lazer, $46 \%$ dos alunos gastam até dez horas semanais, 16\% de dez a vinte horas, e 38\% permanecem acima de vinte horas. Para realização de trabalhos escolares, a frequência de uso do computador para navegação está geralmente em torno de seis a dez horas semanais (84\%).

Relativamente à finalidade do uso do computador em casa, $99 \%$ dos alunos costumam consultar e pesquisar na Internet para realização de trabalhos escolares, $100 \%$ usa para se comunicar via redes sociais, $86 \%$ para acessar e-mails, e somente $3 \%$ dos alunos relataram utilizar somente para realizar trabalhos escolares. Quanto à dinâmica de organização para estudos e realização de trabalhos, $76 \%$ gostam de trabalhar em grupos, enquanto quase a metade dos alunos prefere trabalhar individualmente (48\%).

Essa caracterização permitiu tomar conhecimento das condições com as quais os alunos fazem uso do computador e da Internet, bem como inferir que a maioria dos alunos possuía os conhecimentos básicos para desenvolver o trabalho com o Glogster.

\section{Análise dos dados e discussão}

O questionário referente à opinião dos alunos quanto à utilização do Glogster abordou os seguintes aspectos: i) usabilidade do Glogster; ii) compreensão da aplicação do Glogster; iii) satisfação na utilização do Glogster; iv) adequação do Glogster à atividade realizada. Para indicação do grau de acordo ou desacordo, foi utilizada a escala de Likert, com cinco opções: não concordo totalmente, não concordo, nem discordo nem concordo, concordo e concordo totalmente. Ao responderem um questionário baseado nessa escala, os perguntados especificam seu nível de concordância em relação a um item. Para análise dos dados, as cinco opções de concordância foram agrupadas em três: discordância, indefinição e concordância.

\section{Usabilidade do Glogster}

Quanto à usabilidade do Glogster, foram criadas duas dimensões para análise: a facilidade de manuseio e execução de comandos, e a interface e funcionamento da ferramenta. Em relação à facilidade de manuseio (Quadro 1), 44\% dos alunos consideraram fácil tanto a utilização do Glogster quanto a execução das ações desejadas. Entre os alunos, 73\% declararam ter facilidade para inserção de recursos como imagens, cores e textos no Glogster e $49 \%$ concordaram que os comandos são facilmente executáveis. Frente a esses dados, acredita-se que a escolha e utilização do Glogster como recurso pedagógico foi adequada.

Quadro 1 - Facilidade de manuseio do Glogster. Frequência de respostas (f) e porcentagem (\%) referente ao total de alunos entrevistados $(\mathrm{N}=95)$.

\begin{tabular}{|c|c|c|c|c|c|c|}
\hline \multirow{3}{*}{$\begin{array}{c}\text { Itens } \\
\text { O Glogster é fácil de usar }\end{array}$} & \multirow{2}{*}{\multicolumn{2}{|c|}{$\begin{array}{c}\text { Discordância } \\
\text { f } \quad \%\end{array}$}} & \multicolumn{2}{|c|}{ Indiferente } & \multicolumn{2}{|c|}{ Concordância } \\
\hline & & & $\mathbf{f}$ & $\%$ & $\mathbf{f}$ & $\%$ \\
\hline & 25 & 26 & 28 & 30 & 42 & 44 \\
\hline É fácil executar a ação desejada & 27 & 29 & 26 & 27 & 42 & 44 \\
\hline É fácil inserir imagens, cores e textos & 15 & 16 & 10 & 11 & 70 & 73 \\
\hline $\begin{array}{l}\text { Os comandos são facilmente } \\
\text { executáveis. }\end{array}$ & 24 & 25 & 25 & 26 & 46 & 49 \\
\hline
\end{tabular}

Fonte: elaboração própria com base nos dados coletados através dos questionários aplicados aos alunos.

Em relação à interface e ao funcionamento do Glogster (Quadro 2), a maioria dos alunos considerou a interface agradável (69\%) e intuitiva (45\%), com organização adequada (51\%). 
Quadro 2 - Interface e funcionamento do Glogster. Frequência de respostas (f) e porcentagem (\%) referente ao total de alunos entrevistados $(\mathrm{N}=95)$.

\begin{tabular}{|l|c|c|c|c|c|c|}
\hline \multirow{2}{*}{ Itens } & \multicolumn{2}{|c|}{ Discordância } & \multicolumn{2}{c|}{ Indiferente } & \multicolumn{2}{c|}{ Concordância } \\
& f & \% & f & \% & \multicolumn{1}{c|}{ f } & \% \\
\hline A interface do Glogster é agradável & 5 & 5 & 25 & 26 & 65 & 69 \\
\hline A organização dos menus é adequada & 19 & 20 & 33 & 35 & 43 & 45 \\
\hline O Glogster é intuitivo & 11 & 12 & 35 & 37 & 49 & 51 \\
\hline
\end{tabular}

Fonte: elaboração própria com base nos dados coletados através dos questionários aplicados aos alunos.

\section{Compreensão da aplicação do Glogster}

No que concerne à compreensão dos alunos quanto à aplicação do Glogster (Quadro 3), a maioria dos alunos declarou que essa ferramenta facilita a participação (57\%) e, em parte, facilita o desenvolvimento de competências (50\%). A maioria dos alunos considerou ainda ser vantajosa tanto a possibilidade de ligar vários glogs (71\%) quanto a possibilidade de anexar outros tipos de recursos multimídia (90\%): "O Glogster proporciona um tipo de apresentação diferenciada, mais organizada, na qual a liberdade de anexar arquivos e imagens e a facilidade de abri-los é muito vantajosa. O único problema é que necessita do acesso à Internet para apresentar, pois a conexão do colégio não é das melhores" (Sujeito Aluno 38).

Tais informações são importantes, pois é essencial que os alunos compreendam a finalidade da ferramenta. Quando questionados se a aplicação do Glogster estimula a aprendizagem colaborativa, a maior parte dos alunos (54\%) concordou, como referido por dois alunos: "A dupla pode interagir mais e expor suas ideias melhor" (Sujeito Aluno 8); "Uma facilidade é que os indivíduos trabalham simultaneamente" (Sujeito Aluno 9)

Quadro 3 - Compreensão da aplicação do Glogster. Frequência de respostas (f) e porcentagem (\%) referente ao total de alunos entrevistados ( $N=95)$.

\begin{tabular}{|l|c|c|c|c|c|c|}
\hline \multicolumn{1}{|c|}{ Itens } & \multicolumn{2}{|c|}{$\begin{array}{c}\text { Discordância } \\
\text { f }\end{array}$} & \multicolumn{2}{|c|}{$\begin{array}{c}\text { Indiferente } \\
\text { f }\end{array}$} & \multicolumn{2}{c|}{$\begin{array}{c}\text { Concor- } \\
\text { dância }\end{array}$} \\
\hline O Glogster facilita a participação & 12 & 13 & 28 & 30 & 55 & 57 \\
\hline Facilita o desenvolvimento de competências & 15 & 16 & 32 & 34 & 48 & 50 \\
\hline $\begin{array}{l}\text { A possibilidade de ligar vários } \\
\text { Glogs é vantajosa }\end{array}$ & 10 & 11 & 17 & 18 & 68 & 71 \\
\hline $\begin{array}{l}\text { A possibilidade de anexar outros recursos } \\
\text { (links, vídeos, som) é vantajosa }\end{array}$ & 3 & 3 & 7 & 7 & 85 & 90 \\
\hline $\begin{array}{l}\text { O Glogster estimula a aprendizagem } \\
\text { colaborativa }\end{array}$ & 14 & 15 & 30 & 31 & 51 & 54 \\
\hline
\end{tabular}

Fonte: elaboração própria com base nos dados coletados através dos questionários aplicados aos alunos.

\section{Satisfação na utilização do Glogster}

No que diz respeito à satisfação dos alunos quanto à utilização da ferramenta (Quadro 4), 42\% dos alunos considerou mais fácil criar apresentações com o Glogster. Boa parte dos alunos (42\%) julgou que não necessariamente o Glogster aumentou o nível de concentração aplicado durante o trabalho, apesar de $49 \%$ dos alunos terem gostado de realizar a atividade com a ferramenta para apresentar as informações estudadas: "Foi uma forma de fazer o trabalho muito boa, pois desenvolve o pensamento" (Sujeito Aluno 
10). Entre os alunos, $49 \%$ considerou ter sido divertido aprender usando o Glogster e $47 \%$ gostaria de continuar a utilizá-lo.

Quadro 4 - Satisfação na utilização do Glogster. Frequência de respostas (f) e porcentagem (\%) referente ao total de alunos entrevistados $(\mathrm{N}=95)$.

\begin{tabular}{|l|c|c|c|c|c|c|}
\hline \multicolumn{1}{|c|}{ Itens } & \multicolumn{2}{|c|}{$\begin{array}{c}\text { Discordância } \\
\text { f }\end{array}$} & \multicolumn{2}{c|}{$\begin{array}{c}\text { Indiferente } \\
\text { f }\end{array}$} & \multicolumn{2}{c|}{$\begin{array}{c}\text { Concordância } \\
\text { f }\end{array}$} \\
\hline $\begin{array}{l}\text { Com o Glogster é mais fácil } \\
\text { criar apresentações }\end{array}$ & 27 & 28 & 28 & 30 & 40 & 42 \\
\hline $\begin{array}{l}\text { Senti que me concentrei mais quando estava } \\
\text { trabalhando com o Glogster }\end{array}$ & 33 & 35 & 40 & 42 & 22 & 23 \\
\hline $\begin{array}{l}\text { Gostei de organizar a informação aprendida } \\
\text { através do Glogster }\end{array}$ & 19 & 20 & 30 & 31 & 46 & 49 \\
\hline Foi divertido aprender utilizando o Glogster & 17 & 18 & 31 & 33 & 47 & 49 \\
\hline Gostaria de utilizar o Glogster novamente & 24 & 25 & 27 & 28 & 44 & 47 \\
\hline
\end{tabular}

Fonte: elaboração própria com base nos dados coletados através dos questionários aplicados aos alunos.

\section{Adequação do Glogster à atividade realizada}

Sobre a adequação da ferramenta online à atividade realizada (Quadro 5), a maior parte dos alunos (54\%) gostou de ter utilizado a mesma para o trabalho em pequenos grupos (duplas ou trios). Também, uma boa parte considerou que o produto final ficou mais atrativo (43\%): "O trabalho com o Glogster fica mais criativo" (Sujeito Aluno 20). Entre os alunos, 75\% considerou que a utilização do Glogster foi adequada à atividade desenvolvida. Quando questionados se gostariam de ter utilizado o Glogster sozinhos, $44 \%$ dos alunos concordaram - fato que se pode considerar como reflexo de um certo grau de desorganização das duplas e dos trios durante a realização e a negociação da atividade proposta; como referiram alguns alunos: "Faltou organização do grupo, utilizar o Glogster é bacana, mas individual é melhor ainda" (Sujeito Aluno 5). Quando questionados se a representação do conhecimento através da construção de glogs foi uma perda de tempo, a maioria dos alunos (73\%) discordou. As respostas referentes à participação de todos os integrantes do grupo durante a realização da atividade com o Glogster foram bastante equilibradas (Quadro 5).

Quadro 5 - Adequação do Glogster à atividade realizada. Frequência de respostas (f) e porcentagem (\%) referente ao total de alunos entrevistados $(\mathrm{N}=95)$.

\begin{tabular}{|l|c|c|c|c|c|c|}
\hline \multicolumn{1}{|c|}{ Itens } & \multicolumn{2}{c|}{ Discordância } & \multicolumn{2}{|c|}{ Indiferente } & \multicolumn{2}{c|}{ Concordância } \\
\%
\end{tabular}

Fonte: elaboração própria com base nos dados coletados através dos questionários aplicados aos alunos. 


\section{Organização do trabalho em grupo}

Nesta parte do questionário, foram incluídas perguntas abertas sobre a organização do trabalho, realização das tarefas, negociação e liderança. De modo geral, houve divisão de tarefas e fácil negociação, conforme relatado por dois alunos: "Fomos cada um montando um pouco do trabalho, enquanto os outros dois comparavam as informações trazidas por nós para colocá-las no trabalho. Considero trabalhar com o Glogster bem mais fácil se for feito em trios, pois assim é possível delegar tarefas" (Sujeito Aluno 22); "É bom o trabalho ser feito em duplas para melhor organização e cooperação, e o trabalho fica muito bonito e completo com o Glogster" (Sujeito Aluno 43). Aqui, verifica-se que, apesar da troca de informações e da comunicação entre os estudantes, houve divisão de atividades em alguns momentos. Isso denota que, mesmo sendo o Glogster uma plataforma que permite a interação e a tomada de ações em conjunto de maneira assíncrona, ainda assim, os alunos acabaram dividindo tarefas e delegando atribuições uns aos outros durante a construção dos glogs, uma postura bastante comum na realização de atividades coletivas.

Quando questionados sobre os aspectos positivos da realização da atividade com o Glogster, respostas como as seguintes foram comuns: "O Glogster é bom, pois o trabalho fica mais divertido, descontraído e fácil de realizar. E durante a apresentação há uma maior participação da turma" (Sujeito Aluno 69); "Gosto de trabalhar em dupla porque um ajuda o outro nas dificuldades" (Sujeito Aluno 76); "A aula fica diferenciada, fácil de prestar a atenção, produtiva” (Sujeito Aluno 82). Como pontos negativos da atividade, a quase totalidade dos alunos considera que o fato de ser uma ferramenta online torna o trabalho lento e demorado, devido à necessidade de acesso à Internet.

\section{Considerações finais}

Tomando como referência o ensino de Biologia, os Parâmetros Curriculares Nacionais para o Ensino Médio estabelecem que este seja voltado ao desenvolvimento de competências que permitam ao aluno lidar com as informações, compreendê-las, elaborá-las, refutá-las - quando for o caso -, enfim, compreender o mundo e nele agir com autonomia, fazendo uso dos conhecimentos adquiridos e da tecnologia (BRASIL, 2000, p. 19). Destarte, considera-se que a experiência, a construção dos glogs, viabilizou a interação e a colaboração entre os estudantes, contribuindo para que estes fossem estimulados a argumentar, negociar, participar de forma solidária e construir coletivamente suas aprendizagens, mesmo que tenha ocorrido a divisão de determinadas tarefas no decorrer do trabalho. À medida que os estudantes conheciam e se apropriavam dos recursos da plataforma Glogster, também constituíam-se como sujeitos sociais neste novo contexto.

Com isso, acredita-se que o uso das tecnologias digitais na sala de aula, associadas a um planejamento e a objetivos bem definidos, seja positivo, no sentido de desenvolver a aprendizagem colaborativa e estimular o desenvolvimento de competências. Cabe salientar que, independentemente da tecnologia digital empregada, é necessário que as práticas pedagógicas envolvidas sirvam para que os alunos aprendam a argumentar, a cultivar a visão de que a ciência é controversa, carece de fundamentação e está sempre se renovando. E, enfim, tornem-se pesquisadores.

A inserção das tecnologias digitais na sala de aula torna-se um desafio e deve ser considerada como uma oportunidade de avaliar e questionar o paradigma tradicional de ensino - que deixa de utilizar esses recursos ou que, como frequentemente ocorre, os reduz ao uso do computador e da Internet como uma mera fonte de pesquisa. Neste contexto, torna-se importante criar situações de ensino-aprendizagem com a introdução dessas 
tecnologias em cenários educacionais que, além dos objetivos de aprendizagem, possam desenvolver habilidades relacionadas à construção do conhecimento biológico como: fazer descobertas ou invenções; criar hipóteses e explicações para diversas situações; aplicar e sintetizar informações; e, através da imaginação, construir novos conhecimentos que poderão contribuir para novas descobertas e projetos inovadores.

Por fim, cabe ao professor criar possibilidades para a produção do conhecimento, reforçando a capacidade crítica e criativa do aluno, bem como mantendo uma postura aberta à troca, à participação e à cooperação. Dessa forma, os estudantes podem desenvolver as competências e habilidades necessárias para assumir um papel ativo e colaborativo na construção de suas aprendizagens.

\section{Referências}

BRASIL. Secretaria de Educação Fundamental. Parâmetros curriculares nacionais: Ciências Naturais /Secretaria de Educação Fundamental. Brasília: MEC/SEF, 1998.

Ministério da Educação/Secretaria de Educação Fundamental. Parâmetros Curriculares Nacionais. Brasília: MEC/SEF, 2000.

. Ministério da Educação. Secretaria da Educação Média e Tecnológica. Parâmetros Curriculares Nacionais + (PCN+) - Ciências da Natureza e suas Tecnologias. Brasília: MEC, 2002.

CARVAlHO, Ana Amélia Amorim. Rentabilizar a Internet no Ensino Básico e Secundário: dos recursos e ferramentas Online aos LMS. Sísifo. Revista de Ciências da Educação, n. 3, p. 25-40, 2007.

FREIRE, Paulo. Pedagogia do oprimido. Rio de Janeiro: Paz e Terra, 2011.

LÉVY, Pierre. As tecnologias de inteligência: o futuro do pensamento na era da informática. Rio de Janeiro: Editora 34, 1993.

MORTIMER, Eduardo. Construtivismo, mudança conceitual e ensino de Ciências: para onde vamos? Investigações em Ensino de Ciências, n. 1. v. 1, p. 20-39, 1996.

PEDRANCINI, Vanessa Daiana; CORAZZA-NUNES, Maria Julia; GALUCH, Maria Terezinha Bellanda; MOREIRA, Ana Lucia Olivo Rosas; RIBEIRO, Alessandra Cláudia. Ensino e aprendizagem de Biologia no ensino médio e a apropriação do saber científico e biotecnológico. Revista Electrónica de Enseñanza de las Ciencias, n. 6. v. 2, p. 299-309, 2007. 